Copyright (2015) AIP Publishing. This article may be downloaded for personal use only. Any other use requires prior permission of the author and AIP Publishing. The following article appeared in Journal of Chemical Physics 3/142 (2015) p. 034301 and may be found at http://dx.doi.org/10.1063/1.4905500

\title{
Low energy electron attachment to cyanamide $\left(\mathrm{NH}_{2} \mathrm{CN}\right)$
}

\author{
Katrin Tanzer ${ }^{1}$, Andrzej Pelc ${ }^{2, *}$, Stefan E. Huber ${ }^{1,4}$, Z. Czupyt ${ }^{3}$, Stephan Denifl ${ }^{1, *}$
}

${ }^{1}$ Institut für Ionenphysik und Angewandte Physik, Leopold Franzens Universität Innsbruck, Technikerstr. 25, 6020 Innsbruck, Austria

${ }^{2}$ Marie Curie-Sklodowska University, Institute of Physics, Mass Spectrometry Department, Pl. M. C.-Sklodowskiej 1, 20-031 Lublin, Poland

${ }^{3}$ Ion Microprobe Facility Micro-area Analysis Laboratory, Polish Geological Institute National Research Institute, Rakowiecka 4, 00-975 Warszawa, Poland

${ }^{4}$ Lehrstuhl für Theoretische Chemie, Technische Universität München, Lichtenbergstr. 4, 85747 Garching, Germany

*e-mail: Andrzej.Pelc@poczta.umcs.lublin.pl, Stephan.Denifl@uibk.ac.at

Keywords: cyanamide, $\mathrm{NH}_{2} \mathrm{CN}$, electron attachment, negative ions, carbodiimide 


\section{Abstract}

Cyanamide is a molecule relevant for interstellar chemistry and the chemical evolution of life. In the present investigation dissociative electron attachment to $\mathrm{NH}_{2} \mathrm{CN}$ has been studied in a crossed electron - molecular beams experiment in the electron energy range from about $0 \mathrm{eV}$ to $14 \mathrm{eV}$. In the electron energy range investigated the following anionic species were detected: $\mathrm{NHCN}^{-}, \mathrm{NCN}^{-}, \mathrm{CN}^{-}, \mathrm{NH}_{2}^{-}, \mathrm{NH}^{-}, \mathrm{CH}_{2}^{-}$. The anion formation proceeds within two broad electron energy regions, one between about 0.5 and $4.5 \mathrm{eV}$ and a second between 4.5 and $12 \mathrm{eV}$. A discussion of possible reaction channels for all measured negative ions is provided. The experimental results are compared with calculations of the thermochemical thresholds of the anions observed. For the dehydrogenated parent anion we explain the deviation between the experimental appearance energy of the anion with the calculated corresponding reaction threshold by electron attachment to the isomeric form of $\mathrm{NH}_{2} \mathrm{CN}-$ carbodiimide. 


\section{INTRODUCTION}

Cyanamide is an important compound with significant industrial and agricultural applications. It is applied in pharmaceutical manufactures as well as in the other organic compound production. The most known application of cyanamide and its derivatives (e.g. calcium cyanamide) is its usage as pesticide since more than 100 years. ${ }^{1}$ In fruit crops $\mathrm{NH}_{2} \mathrm{CN}$ is used as a growth inhibitor and stimulator of uniform opening of buds and also as defoliant for some important agricultural plants. ${ }^{2-4}$ As a toxic substance used in the food industry its monitoring in environment and in food is crucial. ${ }^{5}$ Besides of its toxic properties, surprisingly, recently the cyanamide was found to be also a natural product formed in some kinds of plants. $^{4}$

Additionally the $\mathrm{NH}_{2} \mathrm{CN}$ is an important astrophysical molecule observed in the gas clouds of the interstellar medium (ISM) where it is believed to be synthetized by heterogeneous chemistry on interstellar dust grains. ${ }^{6}$ It was also suggested that cyanamide was present on the primitive earth where its production was possible by electron irradiation of methane, ammonia and water mixture or by the ultraviolet irradiation of aqueous $\mathrm{NH}_{4} \mathrm{CN}$. Furthermore it is a possible key compound in the chemical evolution. ${ }^{7,8}$ For example, in the experiments done by Wollin and $\mathrm{Ryan}^{9}$ a mixture of $\mathrm{KNO}_{3}$ and $\mathrm{NH}_{2} \mathrm{CN}$ was treated with $\mathrm{UV}$ radiation and electrical discharges. After such sample treatment the presence of proteins, nucleosides, nucleic acid bases, hydrocarbons and organic esters were confirmed as reaction products. Moreover, the tautomerism between cyanamide and its isomer carbodiiamide ( $\mathrm{HNCNH})$ is very probable, ${ }^{10}$ and the $\mathrm{HNCNH}$ is considered as a condensing agent able to assemble amino acids into peptides in liquid water. ${ }^{11}$ Cyanamide is therefore recognized as a fundamental probiotic and an important precursor molecule in the study of the origin of life. ${ }^{12}$ In addition, cyanamide as one of the simplest organic molecules comprising important organic 
groups (cyano and amide) could also serve as a model molecule for more complex species with biological relevance.

Metal cyanamides, where one or two atoms of hydrogen in $\mathrm{NH}_{2} \mathrm{CN}$ are exchanged with metal atoms, are derivatives of cyanamide and began to attract attention as a novel class of functional materials. ${ }^{13-17}$ For example, silver cyanamide $\mathrm{Ag}_{2} \mathrm{NCN}$ is a new n-type semiconductor with a direct band gap of about $2.3 \mathrm{eV}$, and therefore can utilize visible light. This feature of silver cyanamide has placed it as potentially useful material for solar energy harvesting and optoelectronics.

By the reasons mentioned above it is very interesting and important to study those mechanisms by which cyanamide may be dissociated through the interaction with a surface, ions, photons and like in the present studies, electrons. Moreover, studies of the interactions of $\mathrm{NH}_{2} \mathrm{CN}$ molecules with electrons may help in the explanation of processes in which the metal cyanamides are involved. Although cyanamide seems to be a very significant compound in many aspects of different processes and application, data rarely exist on the electron impact and collision induced dissociation leading to the formation of positive ions ${ }^{18-}$ ${ }^{21}$ and chemical ionization (CI) leading to the formation of both, positive and negative ions. ${ }^{18}$ The major peaks in the positive ion mass spectrum were ions with $\mathrm{m} / \mathrm{z}$ (mass/charge) equal to 44 and 43 (corresponding to the isotope substitution of atoms in the molecule), 42 (parent ion $\left.-\mathrm{NH}_{2} \mathrm{CN}^{+}\right), 41,40,28,27,26,16,15,14,13$ and 12.

To our best knowledge there is no information and data available regarding the energetics of the electron attachment to $\mathrm{NH}_{2} \mathrm{CN}$. In the investigations on negative ion formation upon negative ion chemical ionization (NCI) of cyanamide in an Ion Cyclotron Resonance trap three ion species at $\mathrm{m} / \mathrm{z}=41,40$ and 26 were observed. ${ }^{18}$ The most abundant anion $\mathrm{HN}-\mathrm{CN}^{-}(\mathrm{m} / \mathrm{z}=41)$ was suggested to be formed by either dissociative electron 
attachment (DEA) or by proton abstraction from $\mathrm{NH}_{2} \mathrm{CN}$ which will occur in reaction with other gaseous anions like, e.g., $\mathrm{CH}_{3} \mathrm{COO}^{-18}$

In Ref. [18] only relative abundances in the negative ion mass spectrum were reported and hence the data regarding the energetics of the resonant electron capture by cyanamide is lacking. This additionally encouraged us to perform studies of low energy electron attachment and to determine ion efficiency curve as well as resonance energies for the most abundant fragment anion formed in free electron capture by cyanamide. The experimental results are compared with computed threshold energies using well-established extrapolation methods.

\section{EXPERIMENTAL}

The electron attachment spectrometer used in the present studies comprises of a molecular beam system, a high resolution hemispherical electron monochromator (HEM) and a quadrupole mass filter with a pulse counting system for analysing and detecting the ionic products. The apparatus has been described previously in detail. ${ }^{22}$ Briefly, as the cyanamide sample is solid at room temperature and does not vaporize sufficiently for generation of a molecular beam (the vapor pressure at $293 \mathrm{~K}$ is $0.005 \mathrm{hPa}^{23}$ ), the $\mathrm{NH}_{2} \mathrm{CN}$ sample was heated in a resistively heated oven. The cyanamide sample with a purity of $99 \%$ was purchased from Sigma Aldrich, Vienna, Austria. The evaporated $\mathrm{NH}_{2} \mathrm{CN}$ molecules were then introduced to the crossing region with the electron beam through a copper capillary of $1 \mathrm{~mm}$ I.D.. The anions generated by the electron attachment process were extracted by a weak electrostatic field into the quadrupole mass filter where they were analysed and detected by the channeltron. After crossing the collision region, the remaining electrons were collected by a Faraday plate; the electron current was monitored during the experiments using a picoamperemeter. 
With the present HEM one is able to achieve an energy distribution of up to $35 \mathrm{meV}$ at full width half maximum (FWHM). ${ }^{22}$ To determine the energy spread and to calibrate the energy scale the well-known cross sections for the formation of $\mathrm{Cl}^{-}$or $\mathrm{SF}_{6}^{-}$by electron attachment to $\mathrm{CCl}_{4}$ or $\mathrm{SF}_{6},{ }^{24}$ respectively, can be used. In the present studies $\mathrm{CCl}_{4}$ was used for calibration of the energy scale. The formation of $\mathrm{Cl}^{-} / \mathrm{CCl}_{4}$ is characterized by two main resonances at $0 \mathrm{eV}$ and $0.8 \mathrm{eV} .^{25,26}$ The first one can be used for calibration of the electron energy scale and to determine the electron energy spread (the apparent FWHM represents the energy resolution of the electron beam). In the present experiments the FWHM and the electron current were $150 \mathrm{meV}$ and $20 \mathrm{nA}$, respectively. This relatively low resolution used represents a reasonable compromise between the product ion intensity and the energy spread to resolve resonances in the measured ion yields. The HEM was constantly heated to the temperature of $340 \mathrm{~K}$ in order to prevent surface charging. Prior to the investigations, the sample of the cyanamide was heated over several hours at the temperature of $303 \mathrm{~K}$. During our experiments the oven temperature was hold at constant temperature of $308 \mathrm{~K}$. At this sample temperature the pressure in the main vacuum chamber of the mass spectrometer was about $10^{-6}$ mbar to ensure collision-free conditions. The sample temperature was below the melting temperature of cyanamide of $319 \mathrm{~K}^{23}$ and significantly below its decomposition temperature of $493 \mathrm{~K}^{27}$ Nevertheless, before the electron capture measurements, the composition of the molecular beam of $\mathrm{NH}_{2} \mathrm{CN}$ was checked for possible traces of its thermal decomposition. For that purpose the positive ion mass spectrum measured by electron ionization at the electron energy of $80 \mathrm{eV}$ was recorded at different temperatures of the sample. These measurements excluded any thermal decomposition of the studied compound. 


\section{QUANTUM CHEMICAL CALCULATIONS}

To complement and support the analysis and interpretation of the experimental results, we used several well-established high-level extrapolation schemes for the calculation of (adiabatic) electron affinities and thermochemical reaction thresholds. In particular, we compared results obtained with $\mathrm{CBS}-\mathrm{QB} 3,{ }^{28,29} \mathrm{G} 4^{30}$ and $\mathrm{W} 1 \mathrm{BD}^{31}$, which are considered to yield very high (and similar) accuracy. More specifically, the CBS-QB3, G4 and W1BD methods achieve mean absolute deviations from experiment of $1.1,0.83$ and $0.48 \mathrm{kcal} / \mathrm{mol}$ for a variety of properties (like atomization energies, electron and proton affinities, etc.) assembled in the G2/97 32,33 (CBS-QB3 and W1BD) and G3/05 $5^{34}(\mathrm{G} 4)$ test sets. A comparison of different extrapolation schemes is often valuable as they might achieve worse performance in exceptional cases than could be reflected by the average accuracy evaluated for selected systems in the respective test sets. The reaction thresholds have been obtained as the difference between all ground state energies of the reaction products (anion and neutral fragments) and reactants (i.e., here, the parent molecule). The computed electron affinities and reaction thresholds are summarized in Tables I and II, respectively. All quantum chemical calculations have been carried out using the Gaussian 09 software. ${ }^{35}$

\section{RESULTS AND DISCUSSION}

Electron attachment to cyanamide is a purely dissociative process with the production of six anionic fragments with m/z of $41\left(\mathrm{NHCN}^{-}\right), 40\left(\mathrm{NCN}^{-}\right), 26\left(\mathrm{CN}^{-}\right), 16\left(\mathrm{NH}_{2}^{-}\right), 15\left(\mathrm{NH}^{-}\right)$, $14\left(\mathrm{CH}_{2}^{-}\right)$. The parent anion $\mathrm{NH}_{2} \mathrm{CN}^{-}$was not observed within the detection limit of the apparatus which would confirm that in the applied experimental conditions the cyanamide 
dimer was not generated. Such dimerization at certain experimental conditions was previously reported by Cacace et al.. ${ }^{18}$ The lack of cyanamide dimer in the $\mathrm{NH}_{2} \mathrm{CN}$ vapour in our experiments was additionally verified by the absence of the dimer ion peak in electron ionization mass spectrum which was recorded prior to the measurements of negative ions.

In Figures 1 and 2 the anion yield curves for all negatively charged fragments observed from cyanamide in the electron energy range of about 0 up to $14 \mathrm{eV}$ are presented. The intensities are given in arbitrary but reproducible units, i.e. the ion signals for all anions are comparable. The ion yields show that the anion formation by DEA to the presently studied compound is represented by resonant electron capture within two broad electron energy ranges, one between about 0.5 to $4.5 \mathrm{eV}$, whereas the second one extends from 4.5 to $12 \mathrm{eV}$. Therefore the anion yield curves were placed in the specific Figures based on the occurrence of DEA in these two electron resonance energies ranges. Table III summarizes the present results concerning the resonance peak positions. In the following paragraphs we will discuss in detail possible production mechanisms for all fragment anions detected.

\section{$\mathrm{CN}^{-}$}

The $\mathrm{CN}^{-}$ion is a frequently observed negative ion species in the ISM, ${ }^{36,37}$ hence it is important to study its formation routes. The formation of the $\mathrm{CN}^{-}$anion from cyanamide - the molecule discovered in the ISM - could provide some insight on the origin of the cyanide ion in interstellar space.

We note that in contrast to the previous NCI studies ${ }^{18}$ the most probable fragmentation reaction of the electron - cyanamide molecule interaction within the studied electron energy range leads to the formation of $\mathrm{CN}^{-}$. In the earlier investigations ${ }^{18}$ the efficiency of $\mathrm{CN}^{-}$ generation was reasonably lower in comparison to the most effectively generated $\mathrm{NHCN}^{-}$. The difference between present and earlier results arises from the various techniques applied in the 
negative ion formation. In Ref. 18 the proton abstraction from cyanamide by gaseous ions was an important process leading to the $\mathrm{CN}^{-}$production, whereas in the present experiments direct interaction between molecules and electrons is involved. Additionally, previously studied electron capture by other nitriles (compounds containing the $\mathrm{CN}$ nitrile group) like $\mathrm{CH}_{3} \mathrm{CN}$, $\mathrm{C}_{2} \mathrm{H}_{3} \mathrm{CN}, \mathrm{C}_{6} \mathrm{H}_{5} \mathrm{CN}$ and $\mathrm{CF}_{3} \mathrm{CN}$ have shown that the $\mathrm{CN}^{-}$anion was the major or one of the major ions generated by the DEA processes. ${ }^{38-40}$ This result is not surprising as the cyano radical $(\mathrm{CN})$ has a high electron affinity of $3.862 \pm 0.005 \mathrm{eV}^{20}$ (our calculated values is 3.90 $\mathrm{eV}$ - see Table I) which is even higher than that for the halogen atoms. However, though we did not determine absolute cross sections in the present experiments, the ion counting rates of $\mathrm{CN}^{-}$in the present case are rather low compared to the halogens anions formed by DEA to halogenated molecules like $\mathrm{CCl}_{4}$. Using ab initio calculations this situation has been explained for previously investigated nitrile molecules by considering their molecular orbital structures and energies. ${ }^{39}$ The highest occupied molecular orbital of radical anions of the nitriles is $\pi^{*}$ antibonding with virtually all the additional charge localized at the nitrile group, resulting in a reduction of $\mathrm{C} \equiv \mathrm{N}$ bond dissociation energy. The $\mathrm{CN}^{-}$ion generation is hence associated with the energy transfer from the $\mathrm{C} \equiv \mathrm{N}$ bond to $\mathrm{R}-\mathrm{CN}$ bond where dissociation into $\mathrm{CN}^{-}$and $\mathrm{R}$ radical in their electronic ground state is symmetry forbidden. For that reason it can only occur through pre-dissociation of the parent anion, and thus the cross section for formation of $\mathrm{CN}^{-}$is relatively low considering the high electron affinity value of $\mathrm{CN}$. In the present studies the $\mathrm{CN}^{-}$ion is formed at two major resonance electron energies peaking at $5.3 \mathrm{eV}$ and $6.4 \mathrm{eV}$. The resonance at $3.6 \mathrm{eV}$ is assigned to an artifact because of DEA to a spurious amount of earlier studied nitroimidazole present in the vacuum chamber. The possible reactions leading to the generation of $\mathrm{CN}^{-}$anion are:

$\mathrm{NH}_{2} \mathrm{CN}+\mathrm{e}^{-} \rightarrow \mathrm{CN}^{-}+\mathrm{NH}_{2}$, 


$$
\mathrm{NH}_{2} \mathrm{CN}+\mathrm{e}^{-} \rightarrow \mathrm{CN}^{-}+\mathrm{N}+\mathrm{H}_{2} \quad,
$$

$$
\begin{aligned}
& \mathrm{NH}_{2} \mathrm{CN}+\mathrm{e}^{-} \rightarrow \mathrm{CN}^{-}+\mathrm{NH}+\mathrm{H}, \\
& \mathrm{NH}_{2} \mathrm{CN}+\mathrm{e}^{-} \rightarrow \mathrm{CN}^{-}+\mathrm{N}+2 \mathrm{H} .
\end{aligned}
$$

The calculations (see Table II) show that DEA channels described by reactions (1a-1d) are all endothermic by $1.20 \mathrm{eV}(1 \mathrm{a}), 4.15 \mathrm{eV}(1 \mathrm{~b}), 5.23 \mathrm{eV}(1 \mathrm{c})$ and $8.65 \mathrm{eV}$ for (1d). From the opposite side the appearance energies (AE) derived from the experimental $\mathrm{CN}^{-}$ion yield curve are $4.0 \pm 0.4 \mathrm{eV}$ (resonance at $5.3 \mathrm{eV}$ ) and $4.3 \pm 0.4 \mathrm{eV}$ for the resonance at $6.4 \mathrm{eV}$. The experimentally obtained AEs fit well with the computational thermochemical thresholds for the reactions (1b) and (1c). Therefore we may accordingly assign the resonances to these different reaction channels (1b) and (1c). However, we cannot exclude that also reaction (1a) may occur which is energetically open at both resonance energies. In this case the fragments released would have a considerable amount of excess energy. The channels represent single and multiple bond cleavage reactions which in one case (reaction $1 \mathrm{~b}$ ) also includes the formation of the $\mathrm{H}_{2}$ molecule. The features at energies $5.3 \mathrm{eV}$ and $6.4 \mathrm{eV}$ are probably caused by Feshbach type core excited resonances. In this case, the incoming electron induces electronic excitation in the target molecule and it is concomitantly trapped for some time in the field of the electronically excited molecule. ${ }^{41}$ Low signal at the mass of $\mathrm{CN}^{-}$was also measured at lower electron energies from $0.5 \mathrm{eV}$ to $3 \mathrm{eV}$. Since this weak signal monotonically rises from threshold, we ascribe it to an artifact instead of a DEA process like reaction (1a). It should be mentioned that in the case of polar molecules with sufficiently high dipole moment, dipole bound negative ion states (DBS) formed at low energies via vibrational Feshbach resonances can serve as doorway states to DEA via coupling with repulsive valence states. ${ }^{42,43}$ Cyanamide has a high dipole moment of $4.32 \mathrm{D},{ }^{20}$ which would be sufficient for the formation of DBS. However, we observe no signature of DBS in the ion yields, and hence 
rule out relevance of such DBS in the formation of present ion yields. Another way to form negative ions at appearance energies below the energetic threshold of the studied molecule could be also the DEA to the impurities of the sample. This will be elucidated in the following paragraphs on the other anions formation from the $\mathrm{NH}_{2} \mathrm{CN}$.

$\mathrm{NH}_{2}^{-}$

The $\mathrm{NH}_{2}{ }^{-}$ion is the second most efficiently formed ion in the low energy electron interaction with the $\mathrm{NH}_{2} \mathrm{CN}$ molecules. The amino radical $\left(\mathrm{NH}_{2}\right)$ negative ion is complementary to the $\mathrm{CN}^{-}$and therefore could be formed in the channels:

$\mathrm{NH}_{2} \mathrm{CN}+\mathrm{e}^{-} \rightarrow \mathrm{NH}_{2}^{-}+\mathrm{CN}$

$\mathrm{NH}_{2} \mathrm{CN}+\mathrm{e}^{-} \rightarrow \mathrm{NH}_{2}^{-}+\mathrm{C}+\mathrm{N}$.

The $\mathrm{NH}_{2}^{-}$ion yield is comparable with that of $\mathrm{CN}^{-}$. The ion yield ratio for these ions equals 0.8. The comparable $\mathrm{NH}_{2}{ }^{-}$and $\mathrm{CN}^{-}$ion signals together with the low electron affinity of $\mathrm{NH}_{2}$ $\left(0.771 \mathrm{eV}^{20}\right)$ confirms the above explanation of the low signal of $\mathrm{CN}^{-}$ion. The amino radical anion formation undergoes at a major resonance with the appearance energy of $4.0 \pm 0.4 \mathrm{eV}$ and maximum at $6.4 \pm 0.2 \mathrm{eV}$. Closer inspection of the ion yield curve indicates that also second resonance peaking at about $9.1 \pm 0.2 \mathrm{eV}$ is visible.

Considering the calculated bond dissociation energies and the electron affinities of fragments involved in reactions ( $2 \mathrm{a}$ and $2 \mathrm{~b}$ ) energy thresholds for both channels have been derived as $4.35 \mathrm{eV}$ and $12.03 \mathrm{eV}$, respectively (see Table II). The measured AE of the $\mathrm{NH}_{2}{ }^{-}$ ion is in agreement with the calculated energy barrier for the first DEA channel (2a) responsible for $\mathrm{NH}_{2}{ }^{-}$formation from the cyanamide molecule. 


\section{NHCN and NCN}

Cyanamide has distinct acidic properties. The results of ICR bracketing experiments showed that $\mathrm{NH}_{2} \mathrm{CN}$ is a stronger acid than for example HF. ${ }^{18}$ Therefore the hydrogen atom or molecule abstraction from the cyanamide molecule should be a very effective process leading to the formation of the negative ions $\mathrm{NHCN}^{-}$and $\mathrm{NCN}^{-}$, respectively. Indeed, we can observe both anions with similar yields in magnitude. Such type of ions, where the $\mathrm{H}$ atom or $\mathrm{H}_{2}$ molecule were separated from the parent molecule were also previously observed in DEA to other nitrile molecules. ${ }^{38,39}$ Moreover, these anion species were the most abundant generated by the electron capture to the nitriles. In earlier NCI studies of cyanamide, the singly and doubly dehydrogenated anions were the two of three anions observed at all. ${ }^{18}$ The $\mathrm{NHCN}^{-}$ anion is formed only in the single DEA channel:

$\mathrm{NH}_{2} \mathrm{CN}+\mathrm{e}^{-} \rightarrow \mathrm{NHCN}^{-}+\mathrm{H}$.

The calculated threshold energy for reaction (3) is $1.52 \mathrm{eV}$. Since in the formation of $\mathrm{NHCN}^{-}$ only a single bond to hydrogen has to be broken, the anion's AE derived from the experimental data has the low value of $1.1 \pm 0.2 \mathrm{eV}$. This is one of the lowest values of AE in the case of anions generated from the $\mathrm{NH}_{2} \mathrm{CN}$. The measured ion $\mathrm{NHCN}^{-}$signal shows that this anion is formed within a broad energy region between 0.5 to $4.5 \mathrm{eV}$ with three resonances of about $1.5 \pm 0.2 \mathrm{eV}, 2.5 \pm 0.2 \mathrm{eV}$ and $3.0 \pm 0.2 \mathrm{eV}$ and additionally at higher energy range at resonances with maxima of $5.1 \pm 0.2 \mathrm{eV}$ and $9.1 \pm 0.2 \mathrm{eV}$. The plurality of resonance features leading to the $\mathrm{NHCN}^{-}$anion generation ratifies that this ion formation proceeds also via electron attachment to the different states of the excited molecule. Another possibility which could explain the variety of energies at which the $\mathrm{NHCN}^{-}$is formed and the wealth of resonance features is DEA to isomeric forms of cyanamide. Especially the broad and structured energetic feature at low energies may lead to this assumption as well as the observation of ion yield below the thermodynamic threshold for this channel. The previous 
studies of the properties of $\mathrm{NH}_{2} \mathrm{CN}$ have shown that in most cases the purchased or obtained cyanamide samples were usually contaminated with the isomeric form of the cyanamide carbodiimide (HN-C-NH). ${ }^{18,21}$ IR spectroscopy of cyanamide in the gas phase also indicates that its tautomer carbodiimide is present as a minor constituent. ${ }^{44}$ It has been reported previously that cyanamide-carbodiimide isomerization can occur in the gas phase for temperatures higher than $293 \mathrm{~K}^{45}$ In our experimental conditions, the vaporisation temperature of the sample was almost $20 \mathrm{~K}$ higher, allowing the $\mathrm{HN}-\mathrm{C}-\mathrm{NH}$ formation. Calculations $^{46}$ have shown that the equilibration of cyanamide and carbodiimide is a bimolecular reaction as the intramolecular tautomerization involves high energetic barrier of $90 \mathrm{~kJ} / \mathrm{mol}$. Recently it has been measured that considered isomerization process can occur in the presence of water. ${ }^{11}$ Using the FT-IR spectroscopy Duvarnay et al. ${ }^{11}$ have shown that even at very low temperatures $(10$ to $140 \mathrm{~K})$ in the water environment the carbodiimide could be formed from cyanamide. The study of Tordinii et al. ${ }^{46}$ predicts that the cooperative effect of only a few water molecules leads to a drastic reduction of the tautomerization barrier, allowing then formation of carbodiiamide. In the present experiment cyanamide molecules have the possibility of interaction with water molecules from the residual moisture in the vacuum chamber since it is well known that (a low amount of) residual water molecules are almost always present in the mass spectrometers. Several effects observed during the studies of electron attachment to $\mathrm{PtBr}_{2}$ or $\mathrm{SF}_{6}{ }^{47,48}$ confirm interaction of molecules under study and residual water molecules. Moreover, for $\mathrm{CH}_{2} \mathrm{~N}_{2}$ five other isomeric neutrals identified as stable species in the gas phase exist (excluding carbodiimide): diazomethane, nitrilimine, isocyanamide, diazirine and isodiazerine. ${ }^{21,49}$ As these five isomers have low abundance, they have a very weak influence on the negative ion formation in our experiments. Computational results have shown that cyanamide is the $\mathrm{CH}_{2} \mathrm{~N}_{2}$ isomer of lowest energy and therefore most stable. ${ }^{21}$ The present calculations show an energy difference of $0.16 \mathrm{eV}$ between cyanamide 
and carbodiimide. If the latter isomer is present in the beam of neutral molecules before the interaction with the electron beam the DEA thresholds will be consequently lower. In addition, if the energy thresholds for the specific anion formation from the most stable isomers of $\mathrm{CH}_{2} \mathrm{~N}_{2}$ will be close we may observe also in the ion yield the close, overlapping resonances.

The $\mathrm{NCN}^{-}$anion may be formed by the two following DEA channels:

$$
\begin{aligned}
& \mathrm{NH}_{2} \mathrm{CN}+\mathrm{e}^{-} \rightarrow \mathrm{NCN}^{-}+\mathrm{H}_{2}, \\
& \mathrm{NH}_{2} \mathrm{CN}+\mathrm{e}^{-} \rightarrow \mathrm{NCN}^{-}+2 \mathrm{H} .
\end{aligned}
$$

The present thermochemical calculations for the NCN fragment anion show that reaction (4a) is possible at electron energies above $0.80 \mathrm{eV}$, whereas the channel (4b) is only accessible for electron energies exceeding $5.30 \mathrm{eV}$. The experimental $\mathrm{NCN}^{-}$ion yield shows that the formation of this anion is characterized by one low energy resonance with AE of 1.2 $\pm 0.2 \mathrm{eV}$ and the maximum at $1.5 \pm 0.2 \mathrm{eV}$ and three interfering resonances in a wide energy region of about $4 \mathrm{eV}$ to $11 \mathrm{eV}$ peaking at $5.3 \pm 0.2 \mathrm{eV}, 6.1 \pm 0.2 \mathrm{eV}$ and $7.9 \pm 0.2 \mathrm{eV}$. These data show that for the first resonance with $\mathrm{AE}=1.2 \pm 0.2 \mathrm{eV}$ reaction (4a) is energetically accessible and hence we ascribe the first resonance to this reaction channel. The weak resonance at $5.3 \mathrm{eV}$ representing a weak shoulder within a broader structure has an onset slightly below the computed threshold for reaction (4b) and hence a possible reason for the $\mathrm{NCN}^{-}$formation at this energy is DEA to carbodiiamide.

\section{$\mathrm{NH}_{2} \mathrm{C}^{-}$or $\mathrm{NCH}_{2}^{-}$and $\mathrm{NHC}^{-}$or $\mathrm{NCH}^{-}$}

The formation of two other ions (with stoichiometric structures of $\mathrm{NH}_{2} \mathrm{C}^{-}$or $\mathrm{NCH}_{2}^{-}$ and $\mathrm{NHC}^{-}$or $\mathrm{NCH}^{-}$, respectively) possibly formed in DEA to cyanamide would require the loss of one nitrogen atom from the neutral parent molecule. Anion yield at the mass of $\mathrm{NH}_{2} \mathrm{C}^{-}$ $(\mathrm{m} / \mathrm{z}=28)$ is observed in the low electron energies region $<4 \mathrm{eV}$. Concerning $\mathrm{NHC}^{-}$anion 
generation, where additional energy is needed for the $\mathrm{H}$ atom separation, we obtained ion signal at $\mathrm{m} / \mathrm{z}=27$ with a resonance present in the electron energy region from about 4 to 10 $\mathrm{eV}$. However, as discussed below, we ascribe this ion yield to the isotope of $\mathrm{CN}^{-}$.

The heavier anion could be generated in a single channel reaction:

$\mathrm{NH}_{2} \mathrm{CN}+\mathrm{e}^{-} \rightarrow \mathrm{NH}_{2} \mathrm{C}^{-}+\mathrm{N}$.

However, the present calculations yield no energetically stable anion for $\mathrm{NH}_{2} \mathrm{C}$ (see Table I), and thus we exclude the formation of this fragment anion. In contrast, the $\mathrm{NCH}_{2}$ turns out to be stable in its anionic form, since the calculated electron affinity of the neutral is $0.50 \mathrm{eV}$. The corresponding threshold energy for $\mathrm{NCH}_{2}{ }^{-}$formation is $5.43 \mathrm{eV}$ and hence in energy considerably above the ion yield observed experimentally. Hence, we ascribe the ion yield observed rather to an impurity. It should be also noted that the ion yield is the weakest among all mass separated ones observed, i.e. the cross section for this fragment anion would be extremely low.

In the $\mathrm{NHC}^{-}$anion case a hydrogen atom has to be lost from the parent molecule too. In theoretical studies of positive ion generation ${ }^{21}$ it has been predicted that the positive ion with $\mathrm{m} / \mathrm{z}=27$ could have two possible bond structures: $\mathrm{HC} \equiv \mathrm{N}^{+}$and $\mathrm{HN} \equiv \mathrm{C}^{+}$. In the present case the reactions leading to anion formation could be written as follows:

$\mathrm{NH}_{2} \mathrm{CN}+\mathrm{e}^{-} \rightarrow \mathrm{NHC}^{-}+\mathrm{NH}$

$\mathrm{NH}_{2} \mathrm{CN}+\mathrm{e}^{-} \rightarrow \mathrm{NHC}^{-}+\mathrm{N}+\mathrm{H}$.

We observed ion yield on $\mathrm{m} / \mathrm{z}=27$, which resembles that of $\mathrm{CN}^{-}$. However, the present calculations indicate that the fragment anion $\mathrm{NHC}^{-}$formed is unstable towards autodetachment, (see Table I). We note that this type of calculations is not able to reproduce very weak dipole bound states. For $\mathrm{NCH}$ a dipole bound state with an electron affinity between 1.5 and $1.9 \mathrm{meV}$ was reported ${ }^{50}$ which was experimentally observed in Rydberg electron transfer spectroscopy. In the present DEA reaction this dipole bound state is not 
accessible and since the relative abundance of the ion yield at $\mathrm{m} / \mathrm{z} 27$ matches with the isotope of $\mathrm{CN}^{-}$, we obtain agreement with the calculations that $\mathrm{NHC}^{-}$should not form.

\section{NH}

The $\mathrm{NH}^{-}$fragment anion is also observed in the present studies of the DEA to cyanamide. The ion yield spectrum is similar to that one for $\mathrm{NH}_{2}{ }^{-}$suggesting that both ions are formed in the overlapping resonances. Similarly to $\mathrm{NH}_{2}^{-}$the $\mathrm{NH}^{-}$could be formed in two resonances, one at $6.4 \pm 0.2 \mathrm{eV}$ and there is also trace signal recognized with the maximum at about $9.1 \pm 0.2$ eV. Moreover, the latter feature is more abundant for $\mathrm{NH}^{-}$. As in the formation of $\mathrm{NH}^{-}$ breaking of additional hydrogen bond in comparison to $\mathrm{NH}_{2}{ }^{-}$is required, the measured $\mathrm{AE}$ for it is higher by about $0.9 \mathrm{eV}$ than the ones for the $\mathrm{NH}_{2}{ }^{-}$and is equal of $4.5 \pm 0.2 \mathrm{eV}$. The possible DEA channels at which $\mathrm{NH}^{-}$is formed are:

$$
\begin{aligned}
& \mathrm{NH}_{2} \mathrm{CN}+\mathrm{e}^{-} \rightarrow \mathrm{NH}^{-}+\mathrm{NHC}(\text { or } \mathrm{NCH}) \\
& \mathrm{NH}_{2} \mathrm{CN}+\mathrm{e}^{-} \rightarrow \mathrm{NH}^{-}+\mathrm{CN}+\mathrm{H} \\
& \mathrm{NH}_{2} \mathrm{CN}+\mathrm{e}^{-} \rightarrow \mathrm{NH}^{-}+\mathrm{C}+\mathrm{NH} \\
& \mathrm{NH}_{2} \mathrm{CN}+\mathrm{e}^{-} \rightarrow \mathrm{NH}^{-}+\mathrm{CH}+\mathrm{N} . \\
& \mathrm{NH}_{2} \mathrm{CN}+\mathrm{e}^{-} \rightarrow \mathrm{NH}^{-}+\mathrm{C}+\mathrm{H}+\mathrm{N}
\end{aligned}
$$

The energy balances of reactions (7a-7e) listed in Table II indicate that only reaction (7a) is energetically accessible for the observed resonances. The energetic thresholds of reactions (7b-d) lie far above the AEs observed in the experiment and range from 8.80 to $16.48 \mathrm{eV}$. In reaction (7a) two different neutral fragment structure formations are possible. Depending on the neutral fragment structure, the reaction (7a) is endothermic by $3.26 \mathrm{eV}$ for $\mathrm{NCH}$ and 3.92 $\mathrm{eV}$ in the case of NHC, respectively. Since these thresholds are relatively close to each other and the experimental onset is $>4 \mathrm{eV}$, a distinct identification of the neutral isomer fragment formed in (7a) is not possible from the experimental data. We only note that if we compare 
the structure of the $\mathrm{NCH}$ fragment with the structure of the parent molecule of $\mathrm{NH}_{2} \mathrm{CN}$, one can see that the reaction (7a) with cyanamide as a substrate needs strong molecule rearrangement (breaking of two bonds and creating additional $\mathrm{C}-\mathrm{H}$ bond). The formation of the $\mathrm{NH}^{-}$anion from the carbodiimide may be also considered here, as in the case of the $\mathrm{NH}^{-}$ formation from HN-C-NH only a single bond has to be disrupted.

\section{$\mathrm{CH}_{2}{ }^{-}$}

In the present studies of the DEA to cyanamide also the $\mathrm{CH}_{2}^{-}$ion was detected. Formation of the positive ion with the same structure in EI of cyanamide was also predicted previously by calculations. ${ }^{21}$ This ion needs the strongest rearrangement of the cyanamide molecule among all anions measured in the present studies, as two carbon - nitrogen bonds have to be broken and two carbon - hydrogen bonds have to be formed. Surprisingly despite the large changes in the molecule structure $\mathrm{CH}_{2}{ }^{-}$is observed at low electron energies. The $\mathrm{AE} \mathrm{of} \mathrm{CH}_{2}{ }^{-}$is about 0.5 $\mathrm{eV} \pm 0.2 \mathrm{eV}$ and its formation is observed in a broad energy region, between 0.5 to $5.0 \pm 0.2$ $\mathrm{eV}$. At this range of energy two resonances at energies of $1.0 \pm 0.2 \mathrm{eV}$ and $3.0 \pm 0.2 \mathrm{eV}$ could be recognized. The $\mathrm{CH}_{2}{ }^{-}$anion is also generated in a resonance at higher electron energies characterized by the $\mathrm{AE}$ of $\sim 6.0 \pm 0.4 \mathrm{eV}$ and the maximum efficiency of formation at $9.1 \pm$ $0.2 \mathrm{eV}$. The DEA channels which could be responsible for $\mathrm{CH}_{2}{ }^{-}$formation are:

$$
\begin{aligned}
& \mathrm{NH}_{2} \mathrm{CN}+\mathrm{e}^{-} \rightarrow \mathrm{CH}_{2}^{-}+\mathrm{N}_{2}, \\
& \mathrm{NH}_{2} \mathrm{CN}+\mathrm{e}^{-} \rightarrow \mathrm{CH}_{2}^{-}+2 \mathrm{~N} .
\end{aligned}
$$

The calculated thermodynamic threshold for the reaction (8a) is equal to $2.0 \mathrm{eV}$ and in the case of reaction (8b) $11.74 \mathrm{eV}$. Hence, the formation of a nitrogen molecule in the reaction substantially lowers the threshold, which makes the observation of reaction channel (8a) possible. However, the first resonance found at $1.0 \mathrm{eV}$ must be ascribed to an impurity of the ion yield. In this case we can exclude DEA from hydrocarbons present in the vacuum 
chamber since for these compounds resonances are only found at substantially higher electron energies. $^{51}$

\section{CONCLUSIONS}

Dissociative electron attachment to cyanamide in the gas phase using electron attachment spectroscopy was studied. The resistance of a molecule to ionizing radiation is a important property with respect to chemical evolution processes. In the interaction with low energy electrons the relative ion yields turned out to be low in the case of cyanamide compared to effective electron scavengers and the attachment cross section can be estimated to be on similar magnitudes like that for water. However, if an electron is captured, the formed anion decomposes into a variety of stable fragment anions. Six anionic species were detected in the electron energy range of about $0 \mathrm{eV}$ to $14 \mathrm{eV}$. In this energy region two major resonance ranges at which the anions are formed are accessible, one between $0.5 \mathrm{eV}$ to $4.5 \mathrm{eV}$ and second ones in the range from $4.5 \mathrm{eV}$ to $14 \mathrm{eV}$. The anion generation from $\mathrm{NH}_{2} \mathrm{CN}$ hence proceeds via common temporary negative ion states where $\mathrm{CN}^{-}$and $\mathrm{NH}_{2}^{-}$are the most abundant fragment anions observed. In few cases the comparison with calculated thermodynamic thresholds and the knowledge of electron affinities turned out to be essential. For example, the calculated electron affinities of $\mathrm{NHC}$ and $\mathrm{NCH}$ are negative and hence their anions should not be observable on mass spectrometric timescales. In the case of NHCN the calculated threshold value deviates from the experimental appearance energy of the anion which indicates that not only the DEA to cyanamide is involved. However, based on the assumption that an isomeric form of the cyanamide - carbodiimide may be formed at elevated temperatures or in the water molecules presence, this data incoherency can be explained by the DEA to carbodiimide. 


\section{Acknowledgements}

This work was partially supported by the COST Action MP1002 and the Austrian Research Science Fund FWF (P22665). S.E.H. acknowledges support by the Austrian Fonds zur Wissenschaftlichen Forschung, FWF DK+ project Computational Interdisciplinary Modelling W1227-N16. This work was supported by the Austrian Ministry of Science BMWF as part of the UniInfrastrukturprogramm of the Focal Point Scientific Computing at the University of Innsbruck.

\section{References}

1 C.S. Miller and W.C. Hall, Agricultural and Food Chem. 11/3, 222 (1963).

2 S. Lavee and P. May, Austr. J. Grape and Wine Res. 3, 31 (1997).

3 T. Kamo, K. Kato, S. Abe, M. Hirota, H. Yamata, S. Hiradate, and Y. Fujii, Soil Sci. Plant Nutr. 55, 235 (2009).

4 D. Soltys, A. Rudzińska-Langwald, A. Gniazdowska, A. Wiśniewska, and R. Bogatek, Planta 236, 1629 (2012).

5 X.-M. Cai, H. Zhao, M. Wu, X.-Q. Hu, H.-M. He, C.-P. Zhang, C.-R. Zhang, and Z. Li, Chromatographia 75, 1069 (2012).

6 J.-C. Guillemin, M. Bouyahyi, and E. H. Riague, Adv. Space Res. 33, 81 (2004).

7 G. Steinman, R.M. Lemon, and M. Calvin, Proc. Nat. Acad. Sci. U.S. 52, 27 (1964).

8 A. Schimpl, R.M. Lemon, and M. Calvin, Science 147, 149 (1965). 
9 G. Wollin and W.B.F. Ryan, Biochim. Biophys. Acta 584, 493 (1979).

10 W.C. Schneider, J. Am. Chem. Soc. 72, 761 (1950).

11 F. Duvernay, T. Chiavassa, F. Borget, and J.-P. Aycard, J. Am. Chem. Soc. 126 , 7772 (2004).

12 A. Brack, Adv. Space Res. 24, 417 (1999).

13 W. Zhao, Y. Liu, J. Liu, P. Chen, I-W. Chen, F. Huang, and J. Lin, J. Mater. Chem. A 1, 7942 (2013).

14 R. Riedel, E. Kroke, A. Greiner, A.O. Gabriel, L. Ruwisch, J. Nicolich, and P. Kroll, Chem. Mater. 10, 2964 (1998).

15 O. Reckeweg and F.J. DiSalvo, Z. Anorg. Allg. Chem. 629, 177 (2003).

16 M. Neukirch, S. Tragl, and H.J. Meyer, Inorg. Chem. 45 , 8188 (2006).

17 H.J. Meyer, J. Glaser, L. Unverfehrt, H. Bettentrup, G. Heymann, H. Huppertz, and T. Juestel, Inorg. Chem. 47, 10455 (2008).

18 F. Cacace, G. de Petris, F. Grandinetti, and G. Occhiucci, J. Phys. Chem. 97, 4239 (1993).

19 F. Cacace, G. de Petris, and G. Occhiucci, Org. Mass Spectrom. 27, 161 (1992).

20 NIST Chemistry Webbook. Available from: http://webbook.nist.gov/chemistry.

21 K.J. Jobst, P. Gerbaux, G. Dimopoulos-Italiano, P.J.A. Ruttnik, and J.K. Terlouw, Chem. Phys. Lett. 478, 144 (2009).

22 S. Denifl, S. Ptasinska, B. Sonnweber, P. Scheier, D. Liu, F. Hagelberg, J. Mack, L. Scott, and T.D. Märk, J. Chem. Phys. 10, 104308 (2005).

23 K.-D. Wehrstedt, W. Wildner, T. Guethner, K. Holzrichter, B. Mertschenk, and A. Ulrich, J. Hazz. Mater. 170, 829 (2009).

24 H. Hotop, M.-W. Ruf, M. Allan, and I. I. Fabrikant, Adv. At. Mol. Opt. Phys. 49, 85 (2003). 
25 S. Matejcik, A. Kiendler, A Stamatovic, and T.D. Märk, Int. J. Mass Spectrom. Ion Proc. 149/150, $311(1995)$.

26 M. Braun, S. Marienfeld, M-W. Ruf, and H. Hotop J. Phys. B 42, 125202 (2009).

27 H. Rubalcava, The infrared spectra and structure of cyanamide, $\mathrm{PhD}$ thesis, California Institute of technology, Pasadena, California 1956.

28 J. A. Montgomery Jr., M. J. Frisch, J. W. Ochterski, and G. A. Petersson, J. Chem. Phys. 110, 2822 (1999).

29 J. A. Montgomery Jr., M. J. Frisch, J. W. Ochterski, and G. A. Petersson, J. Chem. Phys. 112, 6532 (2000).

30 L. A. Curtiss, P. C. Redfern, and K. Raghavachari, J. Chem. Phys. 126, 084108 (2007).

31 E. C. Barnes, G. A. Petersson, J. A. Montgomery Jr., M. J. Frisch, and J. M. L. Martin, J. Chem. Theor. Comput. 5, 2687 (2009).

32 L. A. Curtiss, K. Raghavachari, P. C. Redfern, and J. A. Pople, J. Chem. Phys. 106, 1063 (1997).

33 L. A. Curtiss, P. C. Redfern, K. Raghavachari, and J. A. Pople, J. Chem. Phys. 109, 42 (1998).

34 L. A. Curtiss, P. C. Redfern, and K. Raghavachari, J. Chem. Phys. 123, 124107 (2005).

35 M. J. Frisch, G. W. Trucks, H. B. Schlegel, G. E. Scuseria, M. A. Robb, J. R. Cheeseman, G. Scalmani, V. Barone, B. Mennucci, G. A. Petersson, H. Nakatsuji, M. Caricato, X. Li, H. P. Hratchian, A. F. Izmaylov, J. Bloino, G. Zheng, J. L. Sonnenberg, M. Hada, M. Ehara, K. Toyota, R. Fukuda, J. Hasegawa, M. Ishida, T. Nakajima, Y. Honda, O. Kitao, H. Nakai, T. Vreven, J. A. Montgomery, Jr., J. E. Peralta, F. Ogliaro, M. Bearpark, J. J. Heyd, E. Brothers, K. N. Kudin, V. N. Staroverov, R. Kobayashi, J. Normand, K. Raghavachari, A. Rendell, J. C. Burant, S. S. Iyengar, J. Tomasi, M. Cossi, N. Rega, J. M. Millam, M. Klene, J. E. Knox, J. B. Cross, V. Bakken, C. Adamo, J. Jaramillo, R. Gomperts, R. E. Stratmann, O. Yazyev, A. J. 
Austin, R. Cammi, C. Pomelli, J. W. Ochterski, R. L. Martin, K. Morokuma, V. G.

Zakrzewski, G. A. Voth, P. Salvador, J. J. Dannenberg, S. Dapprich, A. D. Daniels, Ö. Farkas, J. B. Foresman, J. V. Ortiz, J. Cioslowski, and D. J. Fox, Gaussian 09, Revision C.01, Gaussian, Inc., Wallingford CT, 2009.

36 V. Vuitton, P. Lavvas, R.V. Yelle, M. Galand, A. Wellbrock, G.R. Lewis, A.J. Coates, J.E. Wahlund, Plan. Space Sci. 57, 1558 (2009).

37 Y.S. Kim and R.I. Kaiser, Astrophys. J. 729, 1 (2011).

38 M. Heni and E. Illenberger, Int. J. Mass Spectrom. Ion Proc. 71, 199 (1986).

39 M. Heni and E. Illenberger, Int. J. Mass Spectrom. Ion Proc. 73, 127 (1986).

40 W. Sailer, A. Pelc, P. Limao-Vieira, N.J. Mason, J. Limtrakul, P. Scheier, M. Probst, and T.D. Märk, Chem. Phys. Lett. 381, 216 (2003).

41 E. Illenberger and J. Momigny, Gaseous Molecular Ions. An Introduction to Elementary Processes Induced by Ionization, Darmstadt, Springer, Steinkopff Verlag, New York, 1992. 42 T. Sommerfeld, Phys. Chem. Chem. Phys. 4, 2511 (2003).

43 A.M. Scheer, K. Aflatooni, G.A. Gallup, and P.D. Burrow, Phys. Rev. Lett. 92, 068102 (2004).

44 M. Birk and M. Winnewisser, Chem. Phys. Lett. 123, 368 (1986).

45 S.T. King and J.H. Strope, J. Chem. Phys. 54, 1289 (1971).

46 F. Tordini, A. Bencini, M. Bruschi, L. De Gioia, G. Zampella, and P. Fantucci, J. Phys. Chem. 107, 1188 (2003).

47 K. Tanzer, A. Pelc, S.E. Huber, M.A. Śmiałek, P. Scheier, M. Probst, S. Denifl, Int. J. Mass Spectrom. 365-366, 152 (2014).

48 A. Pelc, Rapid Communications in Mass Spectrometry 26, 577 (2012).

49 E. Schaefer and M. Winnewisser, Ber. Bunsenges. Phys. Chem. 86, 780 (1982). 
50 S. Ard, W.R. Garrett, R.N. Compton, L. Adamowicz, and S.G. Stepanian, Chem. Phys. Lett. 473, 223 (2009).

51 E. Szymańska, N. Mason, E Krishnakumar C. Matias, A. Mauracher, P. Scheier, S. Denifl, Int. J. Mass Spect. 365-366, 356 (2014).

\section{Table and Figure captions}

\section{TABLE I.}

Adiabatic electron affinities (EA) for the $\mathrm{NH}_{2} \mathrm{CN}$ molecule and relevant neutral fragments as obtained with the different used extrapolation schemes.

\section{TABLE II.}

Thermochemical reaction thresholds for DEA reactions of cyanamide as obtained with the different used extrapolation schemes.

\section{TABLE III.}

Peak positions of resonances observed in the ion yield of fragment anions obtained in dissociative electron attachment to $\mathrm{NH}_{2} \mathrm{CN}$.

\section{FIG. 1.}

Fragment anions observed in DEA to cyanamide which are dominantly formed at higher energy resonances.

FIG. 2.

Fragment anions observed in DEA to cyanamide which appear in low energy features.

\section{Table I.}




\begin{tabular}{|c|c|c|c|c|}
\hline Electron affinities & $\mathrm{G} 4(\mathrm{eV})$ & CBS-QB3 (eV) & W1BD (eV) & NIST (eV) [20] \\
\hline $\mathrm{NH}_{2} \mathrm{CN}$ & -0.88 & -0.82 & -0.80 & - \\
\hline HNCNH & -0.67 & -0.83 & -0.84 & - \\
\hline $\mathrm{NHCN}$ & 2.63 & 2.61 & 2.65 & - \\
\hline $\mathrm{NCN}$ & 2.52 & 2.47 & 2.50 & 2.48 \\
\hline $\mathrm{NCH}_{2}$ & 0.52 & 0.50 & 0.50 & 0.51 \\
\hline $\mathrm{NH}_{2} \mathrm{C}$ & -0.65 & -0.73 & -0.71 & - \\
\hline $\mathrm{NCH}$ & -1.17 & -1.17 & -1.17 & possibly unbound \\
\hline $\mathrm{NHC}$ & -1.06 & -0.99 & -0.96 & - \\
\hline $\mathrm{CN}$ & 3.94 & 3.90 & 3.90 & 3.86 \\
\hline $\mathrm{NH}_{2}$ & 0.77 & 0.71 & 0.75 & 0.77 \\
\hline NH & 0.34 & 0.27 & 0.34 & 0.37 \\
\hline $\mathrm{CH}_{2}$ & 0.64 & 0.62 & 0.64 & 0.65 \\
\hline $\mathrm{HN}_{2}$ & 0.72 & 0.87 & 0.76 & - \\
\hline
\end{tabular}


Table II.

\begin{tabular}{|c|c|c|c|}
\hline Reaction thresholds: $\mathrm{e}^{-}+\mathrm{NH}_{2} \mathrm{CN} \rightarrow$ & G4 (eV) & CBS-QB3 (eV) & $\mathrm{W} 1 \mathrm{BD}(\mathrm{eV})$ \\
\hline $\mathrm{NHCN}^{-}+\mathrm{H}$ & 1.49 & 1.50 & 1.52 \\
\hline $\mathrm{NCN}^{-}+\mathrm{H}_{2}$ & 0.71 & 0.69 & 0.80 \\
\hline $\mathrm{NCN}^{-}+\mathrm{H}+\mathrm{H}$ & 5.22 & 5.24 & 5.30 \\
\hline $\mathrm{NH}_{2} \mathrm{C}^{-}+\mathrm{N}$ & 5.39 & 5.42 & 5.44 \\
\hline $\mathrm{CN}^{-}+\mathrm{NH}_{2}$ & 1.14 & 1.21 & 1.20 \\
\hline $\mathrm{CN}^{-}+\mathrm{NH}+\mathrm{H}$ & 5.14 & 5.24 & 5.23 \\
\hline $\mathrm{CN}^{-}+\mathrm{N}+\mathrm{H}_{2}$ & 4.08 & 4.09 & 4.15 \\
\hline $\mathrm{CN}^{-}+\mathrm{N}+\mathrm{H}+\mathrm{H}$ & 8.59 & 8.64 & 8.65 \\
\hline $\mathrm{NH}_{2}^{-}+\mathrm{CN}$ & 4.31 & 4.41 & 4.35 \\
\hline $\mathrm{NH}_{2}^{-}+\mathrm{C}+\mathrm{N}$ & 12.03 & 12.09 & 12.03 \\
\hline $\mathrm{NH}^{-}+\mathrm{CHN}$ & 3.21 & 3.36 & 3.26 \\
\hline $\mathrm{NH}^{-}+\mathrm{NHC}$ & 3.88 & 3.99 & 3.92 \\
\hline $\mathrm{NH}^{-}+\mathrm{CN}+\mathrm{H}$ & 8.75 & 8.88 & 8.80 \\
\hline $\mathrm{NH}^{-}+\mathrm{NH}+\mathrm{C}$ & 13.01 & 13.16 & 13.07 \\
\hline $\mathrm{NH}^{-}+\mathrm{CH}+\mathrm{N}$ & 12.93 & 13.07 & 12.99 \\
\hline $\mathrm{NH}^{-}+\mathrm{C}+\mathrm{N}+\mathrm{H}$ & 16.46 & 16.56 & 16.48 \\
\hline $\mathrm{CH}_{2}^{-}+\mathrm{N}_{2}$ & 1.96 & 2.06 & 2.00 \\
\hline $\mathrm{CH}_{2}^{-}+\mathrm{N}+\mathrm{N}$ & 11.75 & 11.80 & 11.74 \\
\hline $\mathrm{CH}^{-}+\mathrm{HN}_{2}$ & 6.11 & 6.17 & 6.13 \\
\hline $\mathrm{CH}^{-}+\mathrm{N}_{2}+\mathrm{H}$ & 5.74 & 5.87 & 5.80 \\
\hline $\mathrm{CH}^{-}+\mathrm{NH}+\mathrm{N}$ & 12.08 & 12.21 & 12.13 \\
\hline $\mathrm{CH}^{-}+\mathrm{N}+\mathrm{N}+\mathrm{H}$ & 15.53 & 15.61 & 15.54 \\
\hline
\end{tabular}


Table III.

\begin{tabular}{|l|l|}
\hline Ion & $\begin{array}{l}\text { Observed resonance maxima in } \mathrm{eV} \\
\text { (uncertainty } \pm 0.2 \mathrm{eV} \text { ) }\end{array}$ \\
\hline $\mathrm{CN}^{-}$ & 5.3 and 6.4 \\
\hline $\mathrm{NH}_{2}^{-}$ & 6.4 \\
\hline $\mathrm{NCN}^{-}$ & $1.5,5.3,6.1$ and 7.9 \\
\hline $\mathrm{m} / \mathrm{z} 28$ & 1.0 and 3.0 \\
\hline $\mathrm{m} / \mathrm{z} 27$ & 5.3 and 6.4 \\
\hline $\mathrm{NH}$ & 6.4 and 9.1 \\
\hline $\mathrm{CH}_{2}^{-}$ & $1.0,3.0$ and 9.1 \\
\hline $\mathrm{NHCN}^{-}$ & $1.5,2.5,3.0,5.1$ and 9.1 \\
\hline
\end{tabular}




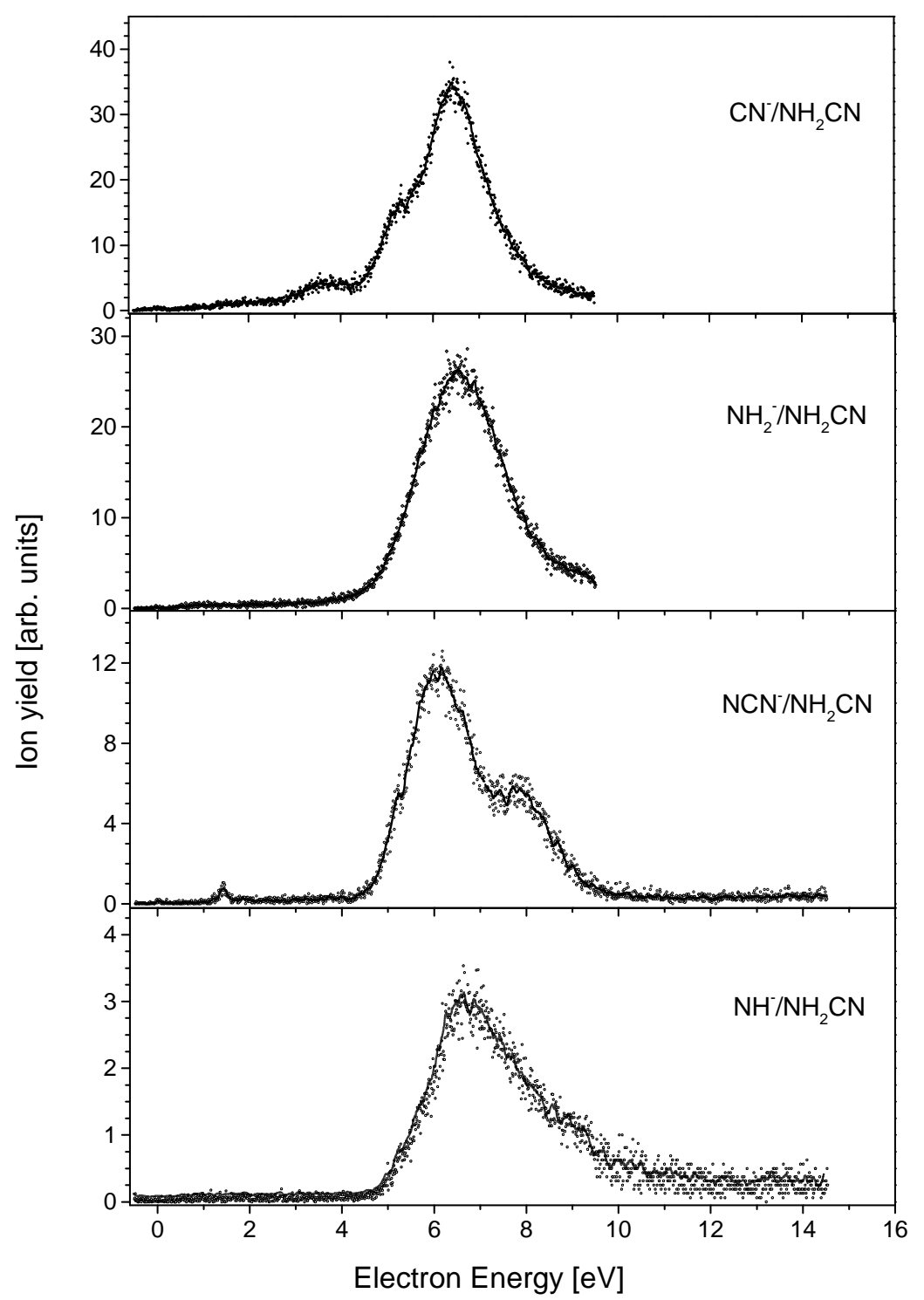


FIG. 2.

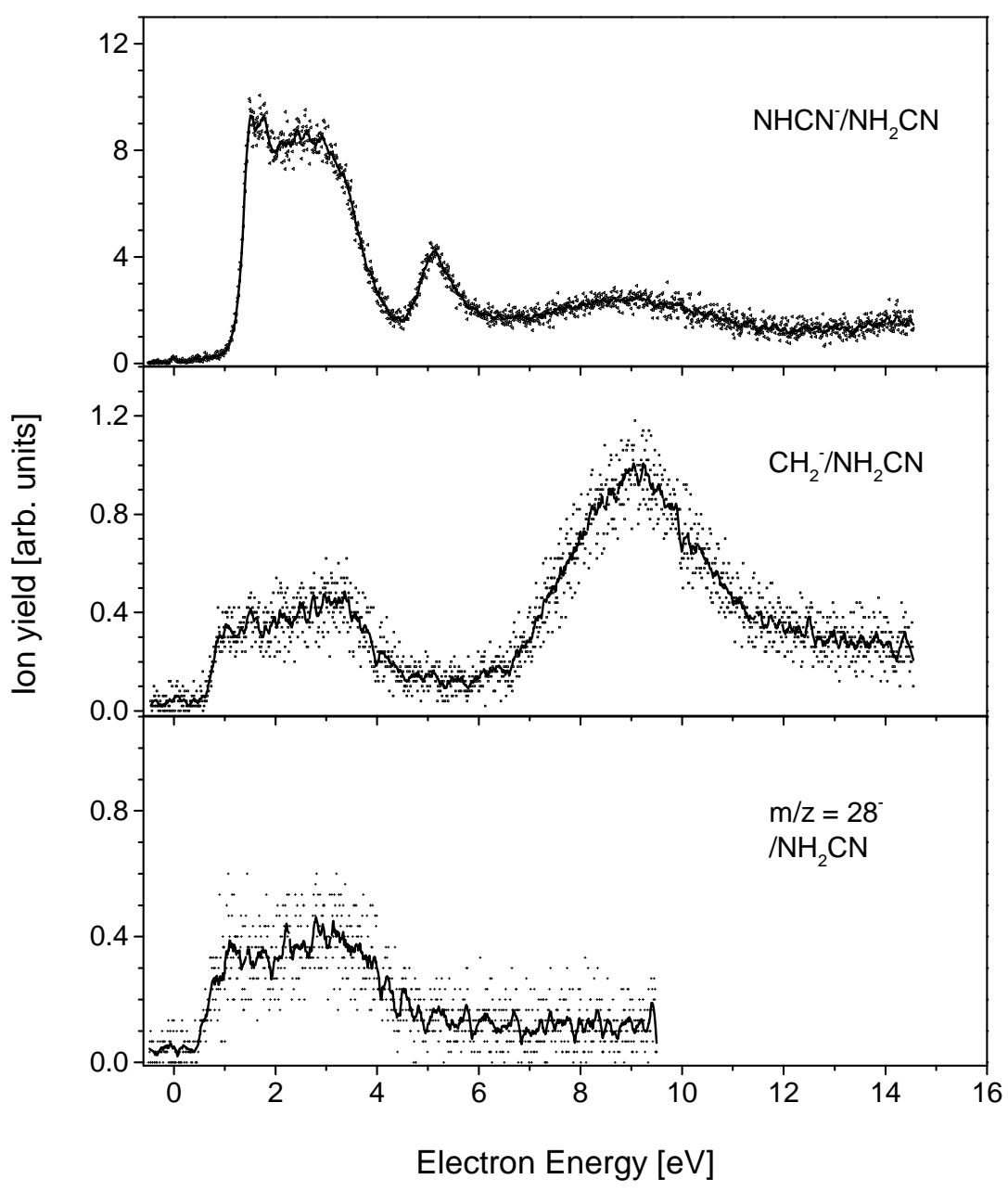

